\title{
EXERGOECONOMIC OPTIMIZATION OF SOLAR HEAT PUMP SYSTEMS OF HEAT SUPPLY
}

\author{
Mexriya Koroly ${ }^{1}$, Anvar Anarbaev ${ }^{2}$, Alisher Usmanov ${ }^{1}$, Kuvondyk Soliev ${ }^{1}$ \\ ${ }^{1}$ Tashkent State Technical University, Universitetskaya, 2, Tashkent, 100002, Uzbekistan \\ ${ }^{2}$ Tashkent Institute of Irrigation and Agricultural Mechanization Engineers, 39 Kari Niyazov, Tashkent, 100000, Uzbekistan
}

\begin{abstract}
In this paper, there is analyzed the results of exergy economic optimization of heat-cooling supply in building by using the solar heat pump system. It is possible to realize a system having high reliability in operation of the system. The solar heat pump system according to the present technical decision has high energy efficiency while ensuring reliability, and is useful as a domestic air conditioning and heating water heater. It can also be applied to uses such as industrial heating and cooling devices.
\end{abstract}

\section{Introduction}

One of the effective ways to save fuel and energy resources is the use of renewable energy sources, primarily solar energy, accumulated through solar collectors in a storage tank. However, the frequency of action and low temperature potential of these sources does not allow using their energy for heating and air conditioning buildings directly without transformations. Heat pump heat supply systems allow increasing the temperature potential of the solar system and compensating for the discrepancy in time between their maximum energy intensity and peak heat consumption. Regardless of the type of heat pump and the type of compressor drive, the consumer receives 1.1 $\div 2.3$ times more heat per unit of consumed initial fuel than with direct combustion of fuel [1]. Such a high efficiency of its production is achieved by the fact that the heat pump involves in its useful use low-potential heat from solar energy in residential buildings with a temperature from +3 to $40{ }^{0} \mathrm{C}$ [2], which cannot be directly used for heat supply.

It is of interest to provide energy supply to buildings based on the combined use of solar thermal collectors and heat pumps.

Heat pumps have great prospects in utilizing the energy of waste low-grade heat of industrial enterprises. For example, the amount of heat transferred to the environment in the cooling towers of the HPP is sufficient to fully cover the city's heat supply demand at outdoor air temperatures down to $-8^{0} \mathrm{C}$ [3].

There are two disadvantages to using heat pumps. The first is associated with the high cost of equipment, amounting to $\$ 200$ per $1 \mathrm{~kW}$ of thermal power [4], although the payback period is $2 \div 3$ years. The second drawback is associated with the cheapness of natural fuel in Uzbekistan. The price ratio of $1 \mathrm{kWh}$ of electricity to $1 \mathrm{~m}^{3}$ of natural gas in Uzbekistan is $0.7 \div 1.2$, and in Europe $-0.4 \div 0.6$ [5]. Such a sixfold excess of the cost of electricity over the cost of gas, of course, cannot be economically explained. Therefore, in the current economic conditions, individual heat supply with the use of heat pumps is much more economical in terms of costs than electric heating, but comparable to gas heating. But when energy prices equalize, which will happen after a while, the use of heat pumps will become undoubtedly beneficial.

\subsection{Schema the solar heat pump system of a heat supply}

Fig. 1 shows a schema of a solar heat pump system [6]. When the temperature in the battery approaches room temperature, temperature control due to the heat in the tank becomes impossible in conventional systems. Under these conditions, the refrigeration compressor can be started to transfer heat from the accumulator to the heat exchanger in the water supply line to the room by means of a pneumatic switch at the outlet of the water temperature regulator.

When the temperature in the accumulator begins to drop below the temperature in the heat exchanger, the differential thermal switch stops circulation through the tank.

In accumulators of solar heating systems, the water temperature during the day can rise to $6^{\circ} \mathrm{C}$. As a result of heat removal from the accumulator during the night, this temperature can drop to $37.8^{\circ} \mathrm{C}$, depending on weather conditions, the size of the accumulator tank, room temperature, etc. Increasing the size of the tank, the thermal capacity of which exceeds 1-2 daily heat demand, may not be economically viable. When a heat 
pump is included in the circuit, the temperature in the battery can be lowered to $0^{\circ} \mathrm{C}$ and in fact double the thermal capacity of the system.

The creation of heat pump compressors and other components requires significant funds; most manufacturers of heat pumps chose the path of using without any modernization of equipment for refrigeration machines of appropriate refrigerating capacity or using extremely expensive imported components [7]. The cost of heat pumps manufactured in the CIS ranges from 90 to 110 thousand US dollars with a heating capacity of 1 Gcal / hour, which is $40 \div$ $320 \%$ lower than the cost of foreign manufacturers [8]. The vapor compression heat pump works as follows. In the evaporator, freon removes heat from the heat carrier of the heat collection system (solar collector), while evaporating and in the vapor state is sucked into the compressor, which is powered by the supplied electricity. In it, the vapor is compressed, as a result of which its thermodynamic potential increases. In the condenser, freon vapors condense, the energy received by it in the evaporator and compressor is released in the form of heat and transferred to the heat carrier of the heating system. For every kilowatt spent on the drive of the compressor, $2.45 \div 4 \mathrm{~kW}$ of heat is supplied to the heating system [9].

The ratio of discharge pressure to suction pressure in reciprocating compressors of refrigeration machines should not exceed [10]

$$
P_{k}=P_{\text {pumping }} / P_{\text {suction }}=6 \div 7 \text {. }
$$

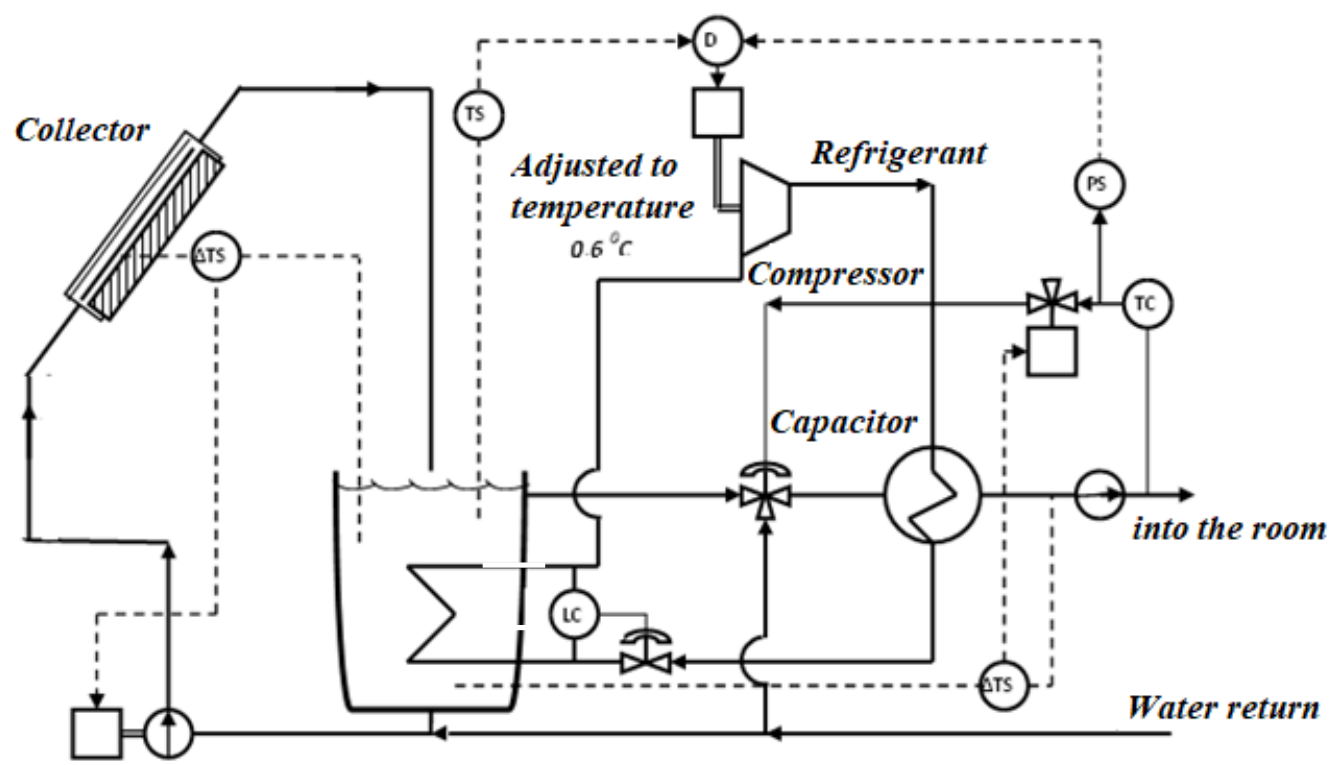

Fig.1. Heat supply system with heat pump: TS - differential temperature controller; TC - temperature regulator; LC level regulator; $\triangle \mathrm{TS}$ - differential thermal switch; PS - pneumatic switch; D - actuator.

\subsection{Comparison of systems heat supply}

The heat pump always has alternative energy supply systems. Compared to traditional energy sources, a heat pump should be a more profitable option for all three comparison criteria (energy, economy, ecology). Table 1 compares the ecological characteristics of various heat supply sources [11]

In fig. 2 shows the schematic diagrams of five systems. The effectiveness of their application is analyzed below.

Table 1. Harmful emissions during the heating season (1448 hours) from various heat sources with a thermal capacity of 1.16 MW [11].

\begin{tabular}{|l|c|c|c|}
\hline \multicolumn{1}{|c|}{ Emission, tons per year } & Coal boiler & Electr heating, gas boiler & Heat pump $(\mu=3,6)$ \\
\hline $\mathrm{SO}_{\mathrm{x}}$ & 21,77 & 38,02 & 10,56 \\
\hline $\mathrm{NO}_{\mathrm{x}}$ & 7,62 & 13,31 & 3,70 \\
\hline Solid particles & 5,8 & 8,89 & 2,46 \\
\hline Fluoride compounds & 0,182 & 0,313 & 0,087 \\
\hline Total & 34,65 & 60,53 & 16,81 \\
\hline
\end{tabular}




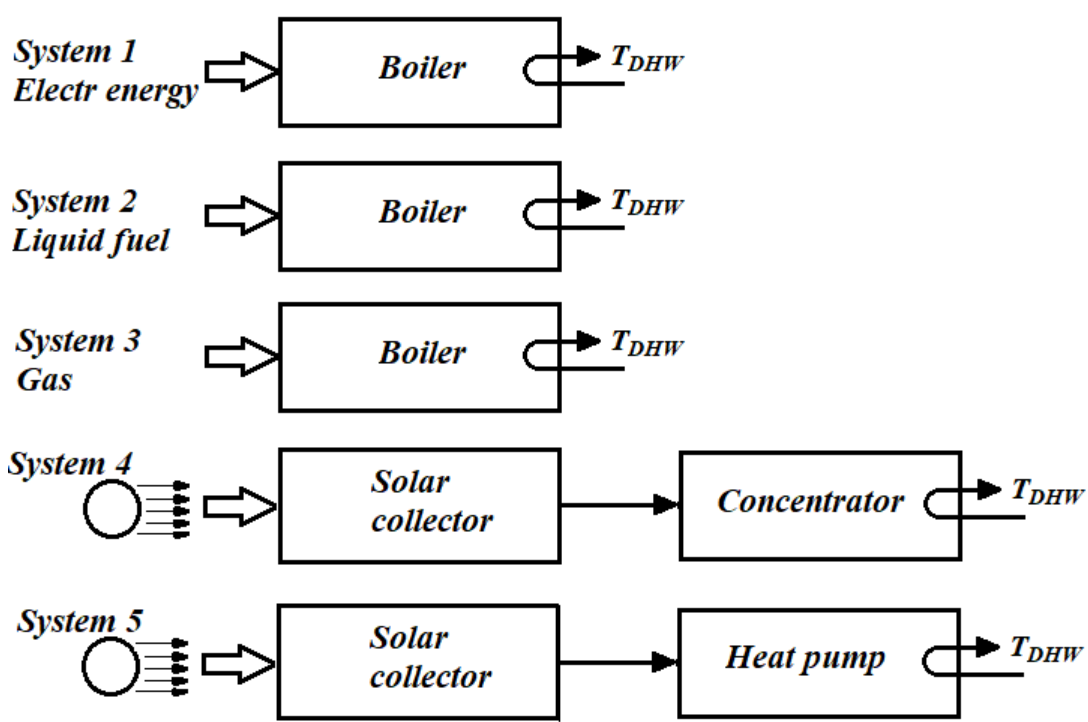

Fig.2... Schematic diagrams of five options for heat supply systems

Thermodynamic model of systems: temperature for the consumer $T=120^{\circ} \mathrm{C}$; temperature of the coolant leaving the solar collector, $T_{c o l}=80^{\circ} \mathrm{C}$; heating capacity of systems $Q_{c}=3 \mathrm{MW}$. The following values were chosen as the average of numerous design and operation experiences of the systems under consideration: Boiler efficiency: on liquid fuel $\eta=0.75$; on gas $\eta=0.70$; adiabatic efficiency of the compressor $\eta_{a d}=0.85$; temperature head in the condenser and evaporator $\Delta T=10^{\circ} \mathrm{C}$ [12]. The total cost of any of the systems under consideration consists of three components - capital, operating costs, and repair and maintenance costs.

\subsection{Method}

The analysis and optimization is based on the solution of the exergoeconomic factor:

$$
f=\frac{Z}{Z+C_{F}\left(E_{D}+E_{L}\right)}
$$

Thus, for the heat pump and its alternative systems, it is additionally necessary to determine the following values: destruction of exergy $E_{D}$ caused by the presence of heat losses $\Delta T$ during heat transfer. We will assume that the loss of exergy $E_{L}$ caused by the presence of a temperature difference between the surface of all vehicles and the environment is absent at this stage of the analysis for all systems shown in Fig. 2. The price of the exergy of the "fuel" $C_{F}$ for the compressor, and therefore for the entire heat pump, is the price of electricity for alternative systems, i.e. drive energy price.

For any element of a heat pump or other system capital costs

$$
Z_{\text {cap.exp. }}=a_{i} x_{i}^{n}(1+b)^{y} / N_{i}
$$

$a$ - unit price; $x-$ element characteristic; $n, y-$ function indicators; $N$ - operation term. Values of parameters $n, y, b, N$ are shown in the table 2 .

Table 2. Parameters of calculations [13]

\begin{tabular}{|l|c|c|c|c|}
\hline \multicolumn{1}{|c|}{ Element } & $n$ & $b$ & $y$ & $N$, years \\
\hline Solar collector & 1 & 0,06 & 4 & 20 \\
\hline Capacitor & 0,95 & 0,06 & 2 & 10 \\
\hline Kondensator & 0,6 & 0,06 & 2 & 15 \\
\hline Evaporator & 0,53 & 0,06 & 16 & 15 \\
\hline Boiler & 0,5 & 0,06 & 16 & 20 \\
\hline
\end{tabular}

Economic characteristics of the system $(a)$ [14]:

\section{Solar collector $13 \mathrm{Euro} / \mathrm{m}^{2}$; \\ Capacitor 292 Euro/kW; \\ Kondensator $13 \mathrm{Euro} / \mathrm{m}^{2}$; \\ Evaporator $\quad 74 \mathrm{Euro} / \mathrm{M}^{2}$;}

Boiler 190,3 Euro/( $\mathrm{kg} \cdot$ hour);

Concentrator 8,4 7-10-6 Euro/kJ;

Drive Energy / Average Purchase Price of Energy:

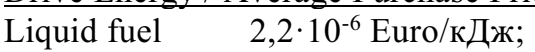

Gas $\quad 3,0 \cdot 10^{-6}$ Euro/кДж;

Electro energy $3,48 \cdot 10^{-2}$ Euro/( $\mathrm{kW} \cdot$ hour $)$.

The values of the technical indicators of the parameters of the elements of a heat pump using water as a working substance and a solar collector to it (characteristic $x$ ):

Solar collector heat exchange surface area $21206 \mathrm{~m}^{2}$; Compressor effective power $587 \mathrm{~kW}$;

Condenser heat exchange surface area $129.2 \mathrm{~m}^{2}$; 
Evaporator heat exchange surface area $102.9 \mathrm{~m}^{2}$; Boiler mass flow rate of liquid fuel $4050 \mathrm{~kg} / \mathrm{h}$; Concentrator heating capacity $3000 \mathrm{~kW}$.

\subsection{Results}

Analyzing the results obtained, we state that at the stage of preliminary design, the efficiency of the heat pump is not much higher than the efficiency of system 2 using liquid fuel. The $3.6 \%$ difference in the total cost of the system is insignificant and falls within the range of the so-called $4 \%$ error allowed by the technical calculation standard. Thus, we conclude that the only alternative to a heat pump can be a liquid fuel boiler. For the future consumer, the idea of using a liquid fuel boiler is traditional and wellstudied from experience. A significant drawback of such a system is the absence of a system of highways for delivering fuel to the consumer. Consequently, there is a need to create a liquid fuel storage system with mandatory safety measures in general and especially fire safety. It is understood that these costs should be included as additional capital and maintenance costs. Naturally, the total costs (system $2+$ storage of liquid fuel) will significantly exceed $3.6 \%$, therefore, the heat pump will be more efficient. Summarizing all the results obtained, we build a streaming exergoeconomic diagram of a solar heat pump system (Fig. 3). Using equation (2), we determine the exergoeconomic factor for each of the systems and compare this indicator (table 3 )

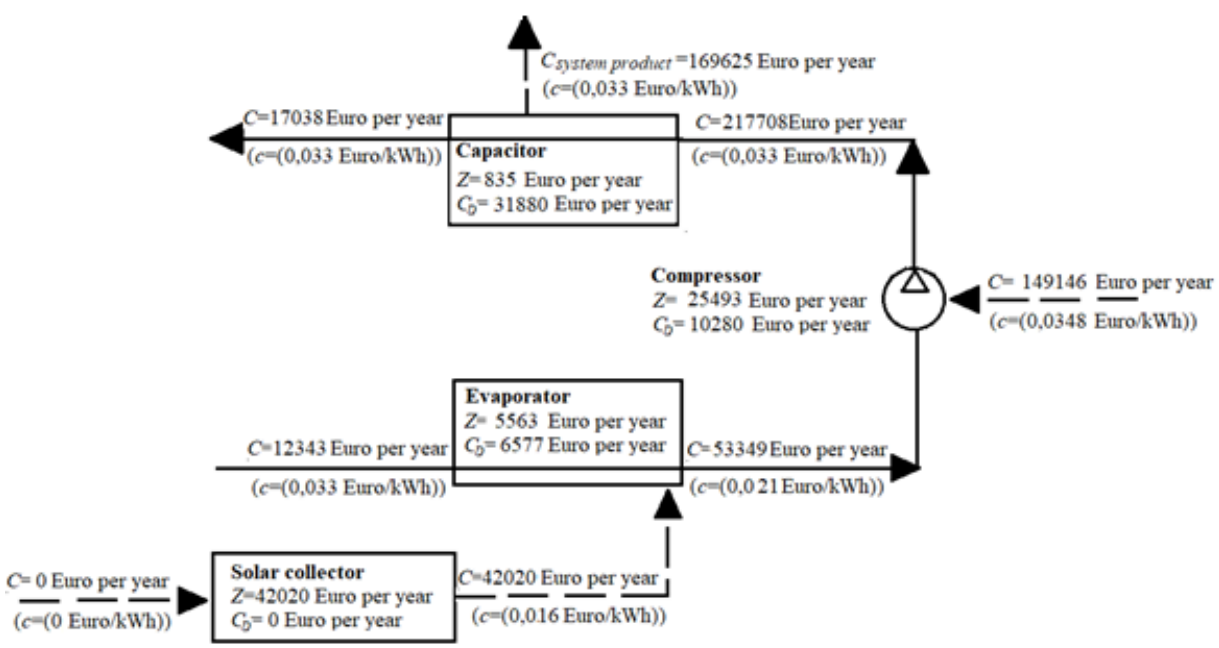

Figure: 3. Stream exergoeconomic diagram of a solar heat pump system

Table 3. Exergoeconomic factor

\begin{tabular}{|c|c|c|c|}
\hline System & $Z_{\text {capital costs, Euro per year }}$ & $Z_{\text {operating costs, Euro per year }}$ & $f$ \\
\hline 1 & 4035 & 734140 & 0,01 \\
\hline 2 & 5044 & 226286 & 0,022 \\
\hline 3 & 5044 & 288000 & 0,017 \\
\hline 4 & 42020 & 556353 & 0,07 \\
\hline 5 & 73911 & 149146 & 0,331 \\
\hline
\end{tabular}

\section{Conclusion}

Thus, the use of heat pump units in centralized and individual heating systems is extremely important. The use of heat pumps for individual heat supply has the following advantages:

- heat pumps are individual heat supply units with the exception of extended heating networks;

- decrease in the volume of natural primary fuel consumed for heat supply by approximately $1.5 \div 2$ times $[15 \div 20]$;

-improvement of the ecological situation in settlements, since the combustion of fuel in urban boiler houses is replaced by the production of electricity outside the settlements, with less fuel consumption for generating electricity than when using boilers;

According to the results of the economic analysis, it is founded that system 1 has the least value of the economic factor. Systems 2 and 3 differ slightly from one another, system 4 is approximately 3.5 times more efficient than systems 2 and 3 . System 5 - heat pump is optimal, since its efficiency is $12 \div 15$ times higher than the efficiency of systems considered as alternatives to it. Based on the eksergoeconomic analysis, we conclude that with the adopted thermodynamic and economic models of systems 1-5, the heat pump + solar 
collector system turns out to be more efficient than others.

\section{References}

1. A.Singh, J.Sarkar, R.R.Sahoo. Experimental performance analysis of novel indirect-expansion solar-infrared assisted heat pump dryer for agricultural products, Solar Energy. 206, (2020) 907-917.

2. S.Ran, W.Lyu, X.Li, W.Xu, B.Wang. A solar-air source heat pump with thermosiphon to efficiently utilize solar energy. Journal of Building Engineering. 31 (2020), 101330.

3. M.Y.Li, B.Li, C.Liu, Sh.Su, Ch.Zhu. Design and experimental investigation of a phase change energy storage air-type solar heat pump heating system. Applied Thermal Engineering.179 (2020), 115506 .

4. J.Yao,W.Liu, L.Zhang, B.Tian, M.Huang. Performance analysis of a residential heating system using borehole heat exchanger coupled with solar assisted PV/T heat pump. Renewable Energy.160(2020) 160-175.

5. J.Ma, A.S. Fung, M.Brands, N.Juan, O.M.A. Moyeed. Performance analysis of indirectexpansion solar assisted heat pump using $\mathrm{CO} 2$ as refrigerant for space heating in cold climate. Solar Energy.208(2020) 195-205

6. R.A.Zakhidov, A.I.Anarbaev. Combined system of solar heating and cooling using heat pump. Applied Solar Energy. 50 (2014) 178-183

7. S.Ran, X.Li, W.Xu, B.Wang. A solar-air hybrid source heat pump for space heating and domestic hot water. Solar Energy.199 (2020) 347-359.

8. Zh.Liu, Q.Wang, D.Wu, Y.Zhang, X.Zhao.Operating performance of a solar/air-dual source heat pump system under various refrigerant flow rates and distributions. Applied Thermal Engineering. 178 (2020) 115631

9. T.T. Chow, G. Pei, et al. Energy and exergy analysis of photovoltaic-thermal collector with and without glass cover, Applied Energy. 86 (2009) 310-316.

10. S. Kratter, Development of an integrated solar home system, Solar Energy Materials \& Solar Cells. 82 (2004) 119-130.

11. Y.J. Wang, X.S. Zhang, Characteristic research and development of solar assisted heat pump water heating system, Refrigeration and airconditioning. 7 (2007) 13-17.

12. J.P. Chyng, C.P. Lee, B.J. Huang Performance analysis of a solar-assisted heat pump water heater, Solar Energy. 74(2003) 33-44.

13. H.D. Fu, G. Pei, J. Ji, Long H, Zhang T and Chow $\mathrm{T}$ T. Experimental study of a photovoltaic solarassisted heat-pump/heat-pipe system, Thermal Engineering. 40 (2012) 343-350.
14. B.J. Huang, J.P. Chyng. Performance characteristics of integral type solar-assisted heat pump, Solar Energy. 71 (2001) 403-414.

15. Y.H. Zhao, H.Y. Wang, et al, Heat transfer characteristics of flat micro-heat pipe array, Journal of Chemical Industry and Engineering (China). (2011) 336-343.

16. G. Wang, Z.H. Quan, Y.H. Zhao, et al, Solar-air composite heat source heat pump hot water system, Journal of Chemical Industry and Engineering (China). 65 (2014) 1033-1039.

17. S.Vaishak, V.B.Purnanand. Photovoltaic/thermalsolar assisted heat pump system: Current status and future prospects. Solar Energy.189 (2019) 268284.

18. CN201363900Y (China) The solar air source heat pumps hot water apparatus. Author: Zeng Zhiyong. Publication date 16. 12.2009

19. .C.Kutlu, Y.Zhang, Th.Elmer, Y.Su, S.Riffat. A simulation study on performance improvement of solar assisted heat pump hot water system by novel controllable crystallization of supercooled PCMs. Renewable Energy.152 (2020) 601-612

20 R.A.Zakhidov, A.I.Anarbaev. Prospects for the further development of solar air-conditioning systems in building. Applied Solar Energy. 49 (2013) 251-256. 